\section{Coming Events}

Due to COVID-19, please check to see if the listed events have been postponed or canceled.

\section{2}

BPS2022: 66th Biophysical Society

Annual Meeting

February 19-23, 2022

San Francisco, CA

https://www.biophysics.org/2022meeting\#

\section{ABRF 2022 Annual Meeting}

March 27-30, 2022

Palm Springs, CA

https://www.abrf.org/abrf-annual-meeting

\section{Experimental Biology 2022}

April 2-5, 2022

Philadelphia, PA

https://www.experimentalbiology.org

7th International Conference on Nanomaterials, Nanodevices,

Fabrication and Characterization (ICNNFC'22)

April 4-6, 2022

Hybrid

Lisbon, Portugal and Virtual

https://icnnfc.com

FIB SEM 2022: 14th Annual Meeting May 4-5, 2022

Laurel, MD

fibsem.net/meetings

EMAS 2022: 17th European Workshop on Modern Developments and

Applications in Microbeam Analysis May 7-11, 2022

Krakow, Poland

www.microbeamanalysis.eu/events/ event/60-emas-2021-17th-european-

workshop-on-modern-developments-andapplications-in-microbeam-analysis

72nd American Crystallographic Association (ACA) Annual Meeting

July 29-August 3, 2022

Portland, OR

acas.memberclicks.net/future-meetings

Microscopy \& Microanalysis 2022

July 31-August 4, 2022

Portland, OR

www.microscopy.org/events/future.cfm

2023

Microscopy \& Microanalysis 2023

July 24-28, 2023

Minneapolis, MN

www.microscopy.org/events/future.cfm

2024

Microscopy \& Microanalysis 2024

July 28-August 1, 2024

Cleveland, $\mathrm{OH}$

www.microscopy.org/events/future.cfm

\title{
A Scorpion's Tail Is No Ordinary Tail!
}

\author{
Stephen W. Carmichael \\ Mayo Clinic, Rochester, MN 55905 \\ carmichael.stephen@mayo.edu
}

Although the scorpion's tail is used as an extremity for hunting, defense, and digging, it is not a modified leg or arm, but an entire body section that has evolved in favor of high mobility. Scorpions have been extremely successful with this strategy for over 400 million years. Rather than being an appendage, the scorpion tail (also called the metasoma) is composed of body segments. The metasoma contains muscles and nerves, as do limbs, but also the terminal portion of the intestines. There are five segments, with the notorious stinger in the fifth segment and the anus in the fourth one.

Even though scorpions are one of the best-studied arthropods, little is known of the functional and constructional aspects of their tails. That has changed thanks to an elegant study by Alice Günther, Manfred Drack, Lionel Monod, and Christian Wirkner [1]. Using micro-computed tomography $(\mu \mathrm{CT})$ and three-dimensional $(3 \mathrm{D})$ reconstruction, they presented the first visualization of the connections between metasomal segments. They simulated the movements of the metasomal segments using modern animation software and then tested the movements using 3D prints (Figure 1).

After surveying many scorpions representing 16 species, Günther et al. chose to investigate the laboratory-bred adult female Mesobuthus cf. gibbosus in detail. This species has a tail typical of most scorpions. Detailed $\mu \mathrm{CT}$ scans were performed using an X-ray microscope. The first four metasomal segments were described as open frustums (truncated cones) with notches for muscle attachments.

The tail is much more flexible and moveable than other body parts. This is facilitated by the hitherto undescribed joint between the last body segment and the first metasomal segment, as well as similar joints between the first four metasomal segments. This newly described articulation has an extensive range of motion in the dorsoventral direction typical of hinge joints, with the additional ability to twist. Functionally, the joint of scorpion tails resembles a hinge joint with two contact surfaces, as one

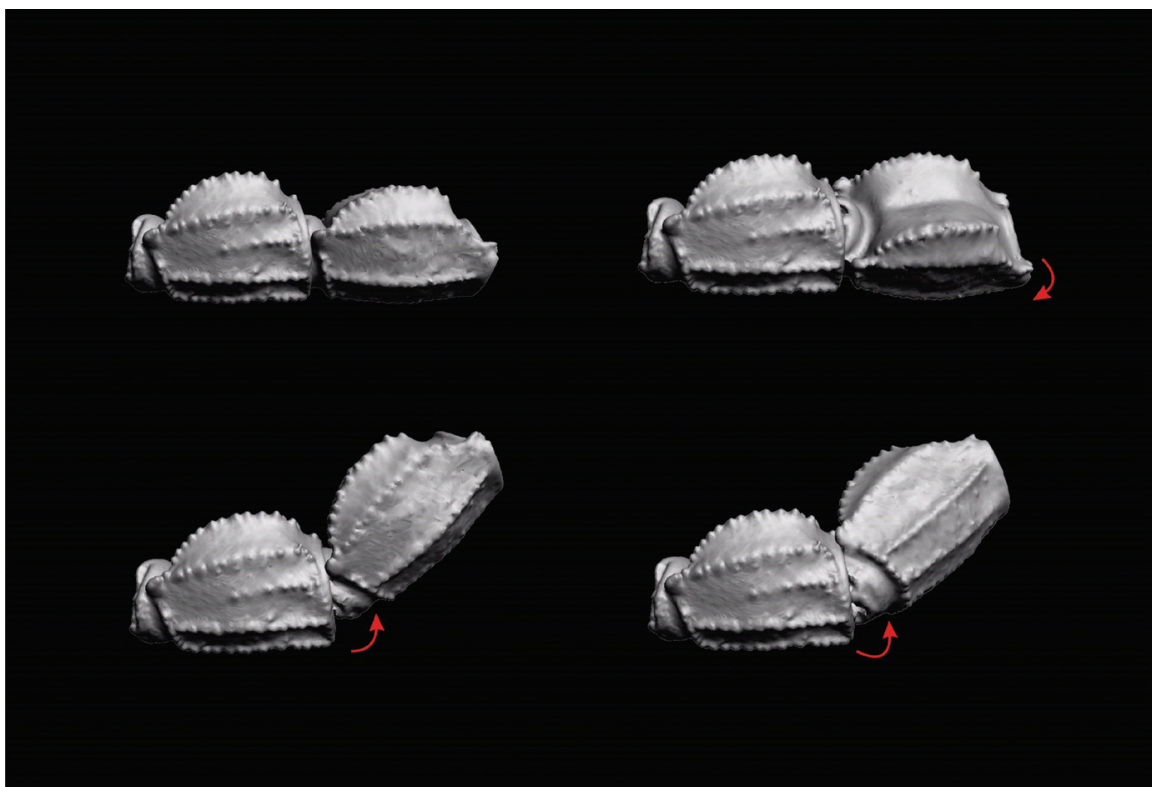

Figure 1: 3D reconstruction and 3D animation of the scorpion Mesobuthus cf. gibbosus have helped to decipher the functional principle of the previously undescribed joint of the scorpion's tail. Shown here are reconstructions of two segments of scorpion tail. The arrows indicate the direction of movement of segment IV against segment III. Magnification: 2×. (Credit: Alice Günther.) 
would find in an arthropod leg. Unlike the hinge joint, however, the joint of the scorpion tails has no socket and no joint head, but two saddle-like structures that slide on an almost circular opening. The principle, which is based on further structural peculiarities, allows the one-dimensional movement of a hinge joint to be extended by the possibility of twisting. Günther et al. suggest that this is best described technically as a "sliding rolling pair" on each side, left and right, since the contact areas of joined segments are used simultaneously for sliding and rolling.

Günther et al. point out that the morphology of the connecting areas of contact are not precisely symmetrical. It is quite interesting to see how "sloppy" biological systems can be but still function very well. These joints provide for quick and precise strikes of the stinger and allow for body tissues to run through the hollow structure of the exoskeleton.

This study not only provides the first description of an arachnid body part, but it also suggests new designs for "soft robotics." This construction could be applicable to industries that require transporting fluids through articulated arms and other applications. It appears particularly well-suited for positioning a device in space with a great deal of precision.

\section{Reference}

[1] Günther et al., J Royal Soc Interface 18 (2021) https://doi .org/10.1098/rsif.2021.0388.

[2] The author gratefully acknowledges Alice Günther, M.Sc. for reviewing this article.

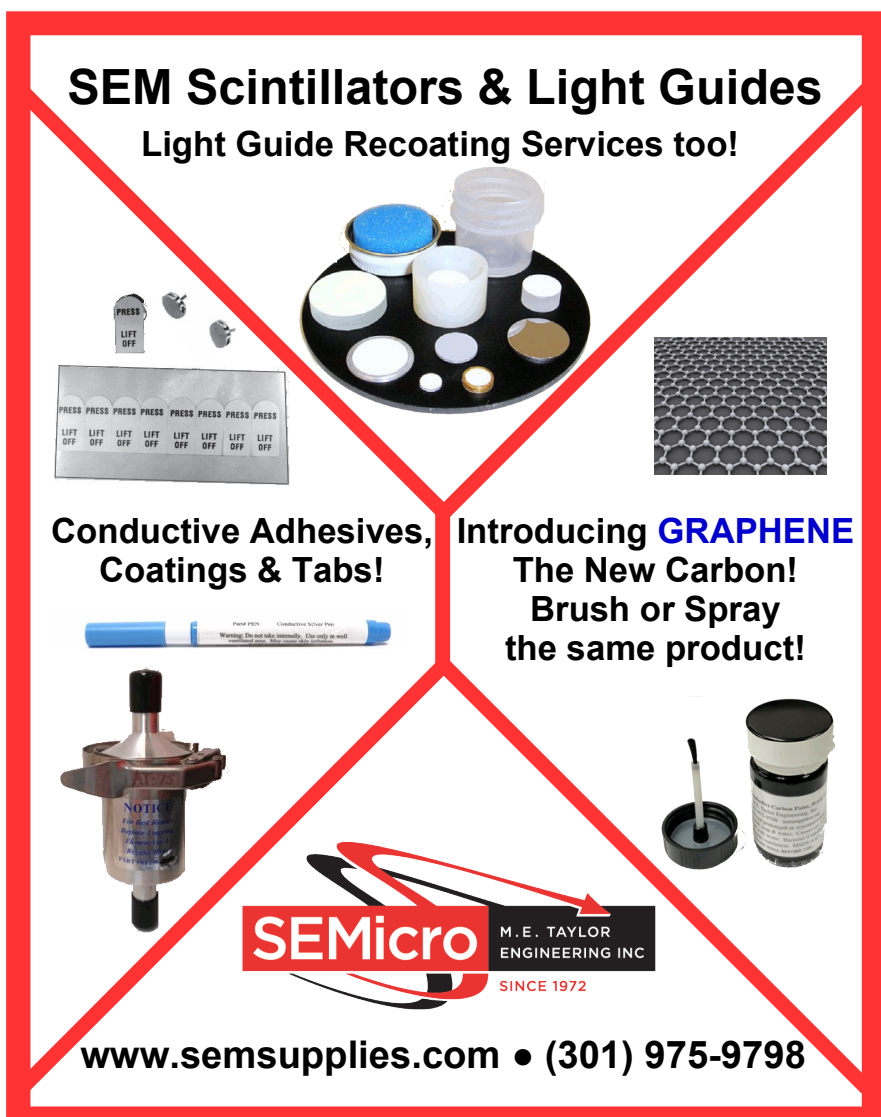

\section{Show Your FIB System Some Love}

High quality extractors, suppressors and aperture strips from Oregon Physics

All parts are made to exacting quality standards for guaranteed performance in your system.

- For FEI/Thermo Fisher Scientific FIB columns

- Reduced costs with volume discounts

- Scheduled deliveries available

- Fast turnaround for urgent requests

- Standard aperture strip configurations
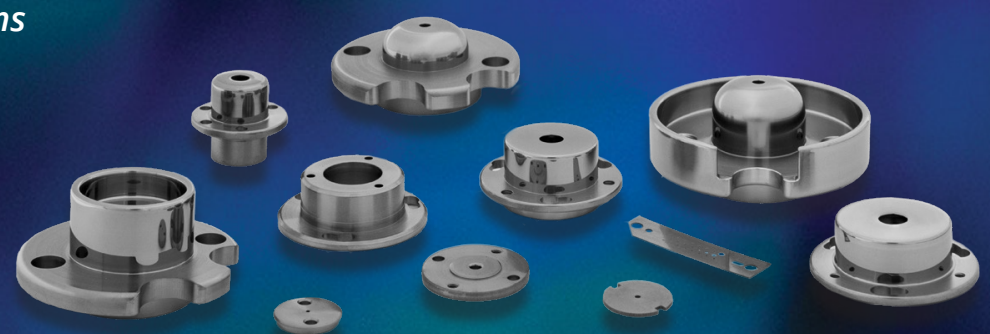

- Made-to-order aperture strips in custom configurations 